$$
\begin{gathered}
\text { 만물네트워크의 사물유저 그룹 관리 기반의 분산원장 } \\
\text { 기술에 대한 연구 } \\
\text { 김수연*†, 강현국** }
\end{gathered}
$$

\title{
Study on Distributed Ledger Technology using Thing-user Group Management of Network of Everything
}

\author{
Suyeon Kim*^ ${ }^{\dagger}$, Hyun Kook Kahng** \\ 요 약
}

본 논문에서는 스마트 계약의 핵심 기술로 사용되는 분산원장 기술의 운영과 분산원장 기술의 구성요소에 대하여 연구하고 분산원장의 요소기술을 차세대 만물네트워크에 적용하기 위한 해결책으로 현재 ISO/IEC $\mathrm{JTC1} \mathrm{SC6}$ 에서 표준화가 진행 중인 만물네트워크 프로토콜의 사물유저 소셜 그룹 관리 기능을 이용한 분산 원장 기술의 프로토콜을 제시하였다. 만물네트워크의 사물유저 소셜 그룹 관리 기능은 안정적인 프로토콜 기 능과 데이터 전송 관리를 제공하고 있으며 멤버 디스커버리기능, 데이터 전송 통로 관리기능 등의 그룹 관리 기능을 제공하고 있다. 분산원장 요소 기술을 상호 합의로 적용할 수 있는 서비스를 제공할 수 있어서 분산 원장 노드들의 그룹 관리 기능에 도움이 될 것으로 예상하며 표준화가 진행되고 있는 ISO/IEC JTC1 SC6의 미래 네트워크 기능과 구조에 적극 반영하고자 한다.

\begin{abstract}
In this paper, We studied the operation of distributed ledger technology used as a core technology for smart contracts and the components of distributed ledger technology. As a solution applying the entity of distributed ledger technology to $\mathrm{NoE}$, we proposed the protocol of the distributed ledger technology using the thing user social group management function of NoE protocols being standardized in ISO/IEC JTC1 SC6. The management function of things user social group in NoE provides stable protocol functions and data transmission management, and provides group management functions such as member discovery function and data transmission channel management function. It is expected to be useful for member management functions of distributed ledger nodes by providing a service that apply the component of distributed ledger technology. We intend to actively reflect this technology in the future network functions of ISO/IEC JTC1 SC6, which is undergoing standardization.
\end{abstract}

한글키워드 : 블록체인, 만물네트워크, 분산원장 기술, 스마트 계약

keywords : Blockchain, Network of Everything, Distributed Ledger Technology, Smart Contract

* 계명대학교 산학협력단

** 고려대학교 전자정보공학과

† 교신저자: 김수연(email: sykim388@gmail.com)

\section{1. 서 론}

접수일자: 2020.09.07. 심사완료: 2020.10.09.

게재확정: 2020.12.21.

핀테크 기반의 새로운 비즈니스 모델로 각광 
받고 있는 스마트 계약의 핵심 프로토콜로써 블 록체인의 분산 원장 기술이 많이 개발되고 있다. 분산원장 응용 기술은 스마트 에너지 분야, 헬스 케어 분야, 국내 또는 국가 간의 세관 관리 분야, 회계 관리 시스템 분야, 스마트 교통 관리 분야, 등으로 광범히 하고 포괄적으로 개발될 것으로 예상된다. 이처럼 산업적 측면에서 활발히 개발 이 이루어지고 있음에도 불구하고 블록체인과 분 산원장 기술은 국제 표준화가 선행되어 이루어지 지 않았다. 표준화가 늦었지만 장기적 관점에서 안정적으로 확산되기 위해서는 다양한 이해 관계 자의 의견을 반영한 국제표준 제정 및 확산이 필 수적임을 공감하였고 또한 글로벌 금융기관들은 파트너십을 통해 블록체인 시스템 구축과 표준 개발을 추진하고 있다. 이를 통한 블록체인과 분 산원장 활성화가 전 세계적으로 이루어질 것으로 예상된다.

블록체인 기술은 다른 영역에서도 적용이 가 능하도록 다양한 블록체인 플랫폼으로 만들어져 운영되고 있기는 하지만 상호간의 호환성 문제는 해결되기 어려웠다[1-2]. 이에 2016년 국제표준화 기구인 ISO, ITU 등에서 블록체인과 분산원장 표준화에 대한 조직이 구성되면서 블록체인과 분 산원장 표준화 활동이 급속도로 증가하기 시작했 고 현재는 블록체인과 분산원장의 용어정의, 세 부 요구사항, 기능 구조, 응용서비스 등 다양한 세부주제로 나누어 활발하게 표준이 개발되고 있 다[3].

한편 국제표준화 기구인 ISO/IEC JTC1 SC6 에서는 미래에 다가올 다양한 지능을 가진 단말 기의 공동작업 환경과 자기 주도적 그룹통신 시 스템을 지원하기 위한 만물네트워크 하부 구조에 대한 연구를 진행하고 있다. 이러한 만물 단말기 의 정보 공유를 지원하고 또한 노드 관리에 필요 한 요구사항을 바탕으로 만물네트워크 프로토콜 표준화가 진행 중이다. 만물네트워크의 기반이
되는 미래 네트워크의 요구사항에 대한 세부적인 내용은 "ISO/IEC TR 29181-series, Problem statements and Requirements" 문서[4]에서 정의 가 되어 있으며 이를 바탕으로 ISO/IEC 21558 미래 네트워크 구조에 대한 표준화와 ISO/IEC 21559 미래 네트워크에 대한 프로토콜과 메커니 즘을 표준화하고 있다[5-6].

최근에 $\mathrm{CD}$ (Committee Draft)로 표준 등록이 완료되었고 다음 단계인 DIS(Draft International Standard) 등록을 추진하고 있는 ISO/IEC 21558 미래 네트워크 구조 문서와 ISO/IEC 21559 미래 네트워크 프로토콜 문서는 표 1 과 같이 3 개의 구 조 문서와 3 개의 프로토콜 문서로 세분화되어 구 성되었다.

표 1. 미래 네트워크 표준화 영역

Table 1. Standardization of Future Network

\begin{tabular}{|c|l|}
\hline 문서번호 & \multicolumn{2}{|c|}{ 제목 } \\
\hline ISO/IEC & Architecture : Switching and \\
$21558-1$ & Routing \\
\hline ISO/IEC & Architecture : Proxy model \\
$21558-2$ & based Quality of Service \\
\hline ISO/IEC & Architecture : Network of \\
$21558-3$ & Everything \\
\hline ISO/IEC & Protocol : Switching and \\
$21559-1$ & Routing \\
\hline ISO/IEC & Protocol : Proxy model based \\
$21559-2$ & Quality of Service \\
\hline ISO/IEC & Protocol : Network of \\
$21559-3$ & Everything \\
\hline
\end{tabular}

본 논문에서는 표 1 의 표준화 영역 중 ISO/IEC 21558-3 Network of Everything (만물 네트워크, $\mathrm{NoE}$ )아키텍처 구조를 기반으로 분산 원장 기술(DLT: Distributed Ledger Technology)을 설계하였고 또한 분산원장을 이 용하려는 그룹의 생성과 관리 기능을 세부적으로 구분한 능력 세트(Capability Set)를 중심으로 동 
작하도록 설계하였다[7]. 그리고 만물네트워크 시 스템에서 다양한 DLT 응용 프로그램이 운영될 경우에 각 DLT 응용프로그램 별로 필요한 멤버 관리와 분산원장 기능 요소의 관리 방법에 대하 여 분석하였다. 이러한 분석을 바탕으로 $\mathrm{ISO} / \mathrm{IEC}$ $\mathrm{JTC1} \mathrm{SC6}$ 에서 표준화가 추진 중인 만물네트워 크에서 블록체인과 DLT 운영에 필요한 프로토 콜 기능을 연계하여 표준화에 적용하고자 한다. 이를 기반으로 만물네트워크에 대한 표준화가 이 루어진다면 블록체인과 함께 최적의 만물네트워 크가 새로운 플랫폼으로 제공되어 사용자에게 안 전한 거래 시스템을 제공할 수 있을 것이라 생각 한다.

이를 위하여 본 논문의 2장에서는 ISO/IEC 21558-3 만물네트워크 표준화 항목에서 프로토 콜 구조 및 노드들의 그룹 관리 기능에 대하여 소개하였다. 그리고 3 장에서는 만물네트워크의 그룹 관리 기능을 이용하여 DLT 프로토콜을 능 력세트로 구성한 프로토콜 구조를 설명하였고 4 장에서는 만물네트워크 표준화에 분산원장 기술 을 지원하기 위한 DLT 그룹 관리 기능과 데이 터 전송 시나리오를 설명하였다. 마지막으로 5장 에서 DLT의 운영을 위해 만물네트워크에 적용 할 요구사항에 대한 결론을 논하고 앞으로의 연 구계획을 제시하였다.

\section{2. 만물네트워크 소개 및 사물 유저 그룹 관리 기능}

\section{1 만물네트워크 프로토콜 소개}

ISO/IEC 21558-3 만물네트워크 구조에 따르면 만물네트워크는 사용자들 사이에 두가지 서비스 를 제공하는데 사물유저 소셜 네트워킹(Thinguser social networking)과 사물유저 중심 통신
서비스(Thing-user centric communication service)이다. 사물유저 소셜 네트워킹이 형성되 면 형성된 소셜 네트워킹에 포함된 사물유저 (Thing-user)는 자신의 능력을 감지할 수 있는 지적인 능력을 소유하고 있으며 이러한 지적 정 보를 다른 사물유저와 서로 공유하여 활용할 수 있다. 사물유저 중심 통신 서비스는 협의된 규약 에 의해 다양한 정보나 필요한 결정에 대한 반응 을 주고받음으로써 공동 작업을 수행할 수 있는 서비스를 제공해 준다.

만물네트워크에서는 이종 망간의 연결에서도 서비스가 정해진 규약으로 동작할 수 있도록 구 성하기 위하여 사물유저 소셜 네트워킹 서비스를 제공하는 Coordinated Networking Layer를 OSI 수송 계층 위에 규정하였다. 그림 1 에서 보는 바 와 같이 Coordinated Networking Layer는 OSI 응용 계층에 위치하고 있고 사물유저의 정보교환 및 경험 정보 공유, Discovery 동작을 수행하게 된다.

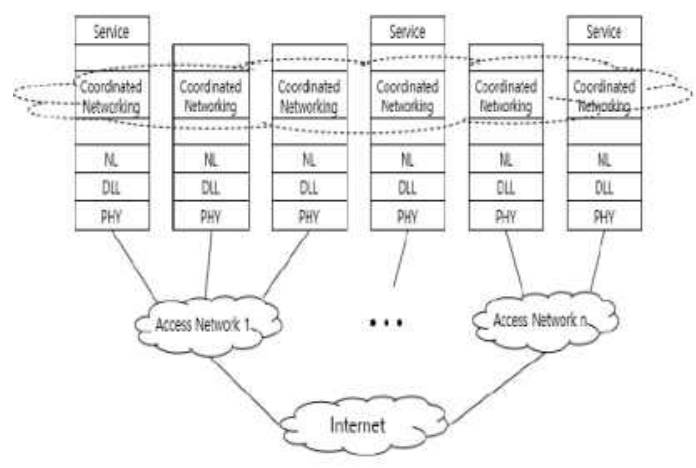

그림 1. 만물네트워크의 계층 구조

Fig 1. Layered Architecture of Network of Everything

2.2 만물네트워크 소셜 유저 그룹 관리 기능

만물네트워크를 지원하기 위하여 Coordinated Networking Layer는 표 2에서 보는 바와 같이 
사물유저 관리 블록, 사물유저 소셜 네트워킹 블 록, 조정된 경험 관리 블록, 조정된 상대노드 발 견 블록, 근접 경로 관리 블록, 사물유저 중심 네 트워킹 제어 블록 등 6 개의 기능 블록으로 구성 된다. 각 기능 블록의 역할은 표 2 와 같다. 이러 한 블록 기능을 통하여 만물네트워크의 노드는 사물유저 소셜 그룹을 형성할 수 있고 사물유저 가 가진 경험을 기반으로 정보 공유를 수행할 수 있으며 필요한 공동 작업을 수행하기 위한 적절 한 상대 사물유저를 발견할 수 있다.

\section{표 2. Coordinated Networking 계층의 기능 블록 Table 2. Functional Blocks of Coordinated Networking Layer}

\begin{tabular}{|l|l|}
\hline \multicolumn{1}{|c|}{$\begin{array}{c}\text { Function } \\
\text { Block }\end{array}$} & \multicolumn{1}{|c|}{ Function } \\
\hline $\begin{array}{l}\text { Thing user } \\
\text { management } \\
\text { Block }\end{array}$ & $\begin{array}{l}\text { To maintain the profile and the status of the } \\
\text { NoE terminals resources and capability skill } \\
\text { set. }\end{array}$ \\
\hline $\begin{array}{l}\text { Thing user } \\
\text { social }\end{array}$ & $\begin{array}{l}\text { To perform the process of organizing or } \\
\text { disbanding a thing-user social community. }\end{array}$ \\
\hline $\begin{array}{l}\text { Coordinated } \\
\text { experience } \\
\text { management }\end{array}$ & $\begin{array}{l}\text { To maintain the coordinated networking } \\
\text { experienced by the NoE terminal and by the } \\
\text { NoE terminals of joined thing-user social } \\
\text { communities }\end{array}$ \\
\hline $\begin{array}{l}\text { Coordinated } \\
\text { p e e r r } \\
\text { discovery }\end{array}$ & $\begin{array}{l}\text { To perform the process of discovering the NoE } \\
\text { terminal to be a peer NoE terminal or the NoE } \\
\text { terminals to form a collaborative work group }\end{array}$ \\
\hline $\begin{array}{l}\text { Prox i m a l } \\
\text { p a t h } \\
\text { discovery }\end{array}$ & $\begin{array}{l}\text { To construct a route between two proximal } \\
\text { end points specified by the thing-user service } \\
\text { control sublayer through the Transport } \\
\text { Network layer }\end{array}$ \\
\hline $\begin{array}{l}\text { Thing user } \\
\text { c e n t r i c } \\
\text { networking } \\
\text { control }\end{array}$ & $\begin{array}{l}\text { To manage the process of socializing a } \\
\text { thing-user and establishing a thing-to-thing } \\
\text { connection }\end{array}$ \\
\hline
\end{tabular}

\section{3. 만물네트워크에서 분산원장 기능 제공을 위한 프로토콜 구조}

만물네트워크 플랫폼에서 다양한 분산원장 응 용 서비스를 제공하기 위한 플랫폼으로 동작할 $\mathrm{DLT}$ 프로토콜을 지원하기 위해서 2장에서 언급
된 6 개의 기능 블록 중에 사물유저 관리 블록의 사물유저 프로파일에 DLT 관련 능력 세트 블록 들을 추가로 적용하여 분산원장 능력 세트를 구 축하고자 한다. 만물네트워크의 소셜 유저 그룹 네트워킹 기능에 DLT APP(Application)을 지원 하고자 할 때 원하는 형태의 DLT 프로토콜이 동 작하는 서비스를 지원하기 위하여 두 가지 절차 가 필요하다. 첫째는 특정한 $\mathrm{DLT}$ 프로토콜을 이 용하고자 하는 사물유저가 DLT 사물유저 그룹 에 참여하고자 할 때 원하는 DLT 프로토콜 능력 세트로 구성된 DLT 사물유저 그룹을 검색하고 적절한 $\mathrm{DLT}$ 프로토콜 능력 세트를 가진 $\mathrm{DLT}$ 사물유저 그룹이 발견되면 참여하게 된다. 둘째 로 $\mathrm{DLT}$ 사물유저 그룹에 참여가 완료되면 참여 하고 있는 다른 사물유저와 DLT 프로토콜 관련 된 능력 정보를 서로 공유하게 된다. 원하는 서 비스 종류에 따라서 하나의 사물유저는 동시에 두개 이상의 $\mathrm{DLT}$ 사물유저 그룹에 참여가 가능 하다. 그림 2에서 보는 바와 같이 다양한 $\mathrm{DLT}$ $\mathrm{APP}$ 이 $\mathrm{DLT}$ 사물유저 그룹으로 연결되어 공동 작업을 수행하는 동안에도 $\mathrm{DLT} \mathrm{APP} \mathrm{내에서} \mathrm{정}$ 보를 교환하면서 필요한 공동 작업을 수행할 수 있다.

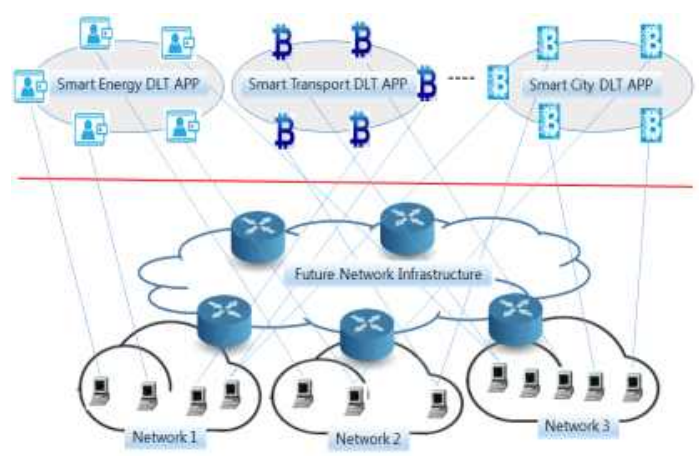

그림 2. 미래네트워크 상에서 DLT 앱 그룹 Fig 2. Group of DLT APP over Future Network

$\mathrm{DLT}$ 사물유저 그룹을 형성한 사물유저는 그 
들의 통신 능력과 DLT 사물유저 그룹에 참여한 동기, 경험, 초현실적 정보를 전달하기 위한 계약 의 의도까지도 공유하게 된다. 전달되는 이름, 주 소, URI, URL과 보안 정보뿐만 아니라 다양한 DLT 프로토콜 관련된 정보도 교환하여 DLT 플 랫폼을 지원하는 소셜 네트워킹을 구축하게 된 다. 그리고 참여한 노드들이 보유한 자원(프로세 싱 파워, 디스크 용량, 네트워크 대역폭 등)을 이 용하여 트랜잭션이 가능하다. 이러한 운영을 지 원하기 위하여 분산원장 기술을 다양한 능력 세 트로 구분하였는데 본 논문에서는 그림 3에서 보 는 바와 같이 수송계층과 응용서비스 계층사이에 DLT 계층을 두고 DLT 계층에 DLT 서비스 제 어 부계층을 중심으로 하여 DLT 능력 세트를 3 개의 부계층으로 분류하여 사물유저의 DLT 기 능을 능력 세트로 구분하였다.

DLT 서비스 제어 부계층은 DLT SAP (Service Access Point)를 통하여 DLT 응용 계 층에 DLT 서비스 기능을 제공한다. 이 부계층 은 DLT 노드의 응용 서비스 요청에 따라 보유한 프로파일을 유지하고 관리하며 3개의 능력 세트 부계층 (DLT 프로토콜 부계층, DLT 데이터 부 계층, DLT 핵심 부계층)과의 연결을 통하여 필 요한 프로파일을 제공하도록 한다.

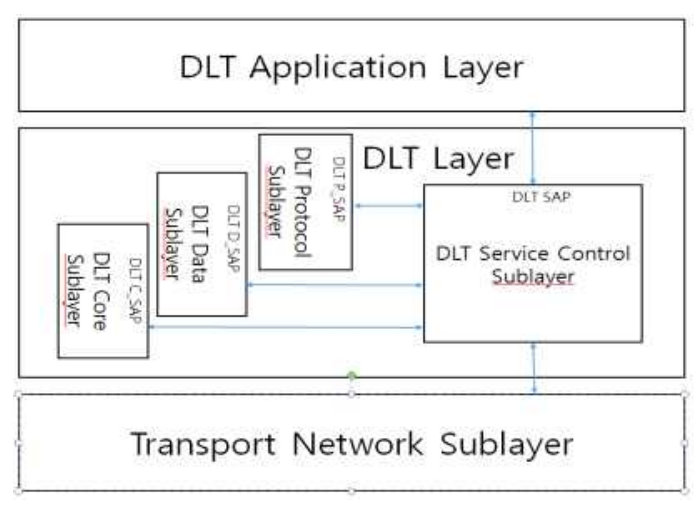

그림 3. DLT 노드의 구조

Fig 3. Architecture of DLT Node
그림 4에서 보는 바와 같이 DLT 프로토콜 부 계층에서의 능력 세트는 블록체인의 중요한 기능 인 컨센서스 프로토콜 기능을 집합으로 가지고 있다. 컨센서스 기능은 DLT의 가장 중요한 요소 이며 다수의 참여자들이 통일된 의사결정을 하기 위해 사용하는 알고리즘을 의미하며 처리되는 데 이터에 대하여 모든 노드들의 합의를 확신하기 위하여 사용된다.

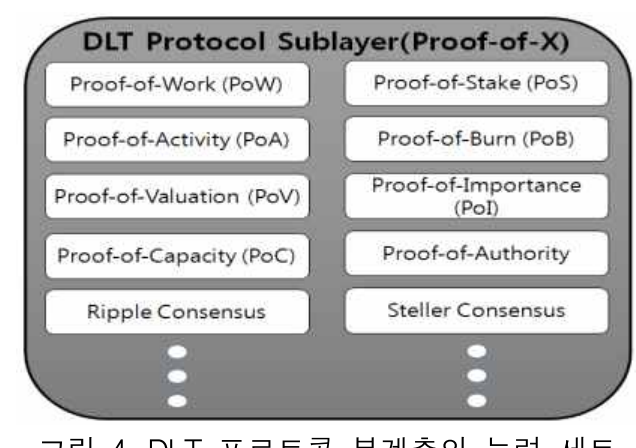

그림 4. DLT 프로토콜 부계층의 능력 세트

Fig 4. Capability set of DLT Protocol Sublayer

그림 5의 DLT 데이터 부계층에서는 블록체인 데이터 처리 기능을 집합체로 가지고 있다. DLT 데이터 부계층에는 다양한 정보가 조합되어 있 다. 계정 정보가 암호화되어 포함되고 계약내용 과 계약방법에 관련된 정보도 데이터로 포함되어 있다. 이러한 데이터를 블록으로 관리하며 블록 의 관리를 위한 헤더 정보도 필요하다.

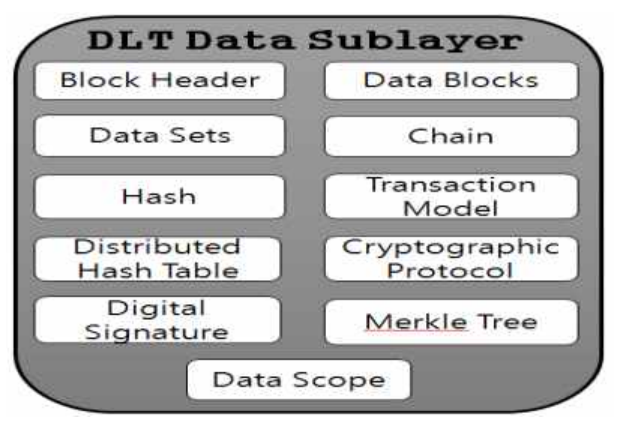

그림 5. DLT 데이터 부계층의 능력 세트 Fig 5. Capability set of DLT Data Sublayer 
그림 6에서는 DLT 응용프로그램과 프로토콜 이 운용될 하부 코어 부계층의 네트워크 능력 세 트를 표시하고 있다. DLT 용용프로그램과 프로 토콜에서 요구하는 기능을 만족할 수 있는 네트 워크 환경을 협상하고 선택하기 위해 존재한다. 이러한 DLT 프로토콜 기능과 관련된 능력 세트 를 보유한 사물유저는 필요한 $\mathrm{DLT}$ 서비스 기능 에 따라 적절한 코어 네트워크 서비스를 협상하 여 $\mathrm{DLT}$ 사물유저 그룹에 참여한다. 참여가 완료 되면 다른 사물유저와 같이 선택한 네트워크를 통하여 DLT 데이터를 교환할 수 있다.

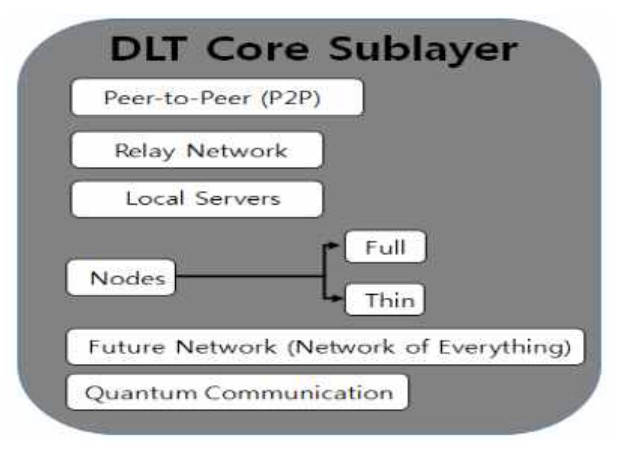

그림 6. DLT 코어 부계층의 능력세트 Fig 6. Capability set of DLT Core Sublayer

\section{4. 만물네트워크에서 분산원장 그룹 관리 기능과 데이터 전송 시나리오}

$\mathrm{DLT}$ 응용 서비스에 따라 DLT 노드는 필요한 능력세트별로 프로파일을 구축하여 DLT 사물유 저 그룹을 형성하게 되고 그룹에서 필요한 $\mathrm{DLT}$ 서비스를 제공하게 된다. 이러한 세부적인 과정 은 다음과 같다.

1) $\mathrm{DLT}$ 사물유저 그룹의 형성: DLT 사물유저 그 룹을 형성하고자 할 때 필요로 하는 사물유저 가 $\mathrm{DLT}$ 사물유저 그룹을 형성하기 위한 최초 의 사물유저가 된다. DLT 등록 서버로부터 정
당한 승인 절차를 거쳐서 DLT 사물유저 그룹 을 생성한 사물유저는 필요한 보안 기능과 $\mathrm{DLT}$ 능력 세트를 가지고 정보를 교환할 수 있 는 그룹을 최초로 형성하게 된다.

2) $\mathrm{DLT}$ 사물유저 그룹에 참여하기: 사물유저가 이미 활동하고 있는 DLT 사물유저 그룹에 등 록하고자 한다면 DLT 능력 세트를 DLT 등록 서버에 전달하여 정보를 교환 협상하고 의도를 포함한 정보를 교환하게 된다. DLT 사물유저 그룹에서 참여를 허락한다면 참여를 할 수 있 게 되고 참여 의도를 그룹에 있는 모든 사물유 저와 공유하게 된다.

3) $\mathrm{DLT}$ 사물유저 그룹에서 작업 경험 공유하기: 사물유저 그룹이 형성되면 DLT 프로토콜을 기반으로 경험이나 지식이 사물유저 멤버들 사 이에 공유된다. 참여하는 멤버들 사이의 프로 세싱 파워나 메모리 양 같은 자원의 차이에 의 해 공유하는 것은 제한될 수 있고 $\mathrm{DLT}$ 능력 세트를 지원하기 위해 특정 자원 또는 능력을 요청하는 멤버에게 적절한 자원과 기능을 할당 할 수 있어야 한다.

4) $\mathrm{DLT}$ 사물유저 그룹에 참여할 노드의 발견: $\mathrm{DLT}$ 사물유저 그룹에 특정의 사물유저가 필 요하면 소셜 그룹의 서버 역할을 수행하는 사 물유저가 참여 대상의 사물유저에 대한 순결성 을 확인하기 위하여 절차를 시작한다. DLT 등 록 서버는 능력 세트 프로파일을 통하여 확인 절차를 가지고 그룹에 참여시키게 된다.

그림 7에서 보는 바와 같이 새로운 DLT 응용 서비스를 사용하고자 하는 사물유저는 미션을 수 행할 수 있는 DLT 사물유저 그룹을 찾아서 가입 하게 된다. 가입을 원하는 사물 유저는 DLT 서 비스를 위하여 필요로 하는 능력 세트를 정의하 여 $\mathrm{DLT}$ 사물유저 그룹에 가입하기 위한 메시지 를 $\mathrm{DLT}$ 계층으로 전달하게 된다. $\mathrm{DLT}$ 계층은 능력세트를 확인하고 문제가 없으면 수신된 메시 
지를 DLT 등록 서버로 메시지를 전달한다. 메시 지를 수신한 등록 서버는 등록된 능력 세트를 확 인하고 가입을 하고자 하는 DLT 사물 유저 그룹 을 찾게 되면 DLT 사물유저 그룹 정보를 전달한 다. 만약 찾지 못한다면 정보를 요청한 사물유저 에게 새로운 DLT 사물 유저 그룹 생성을 하도록 한다.

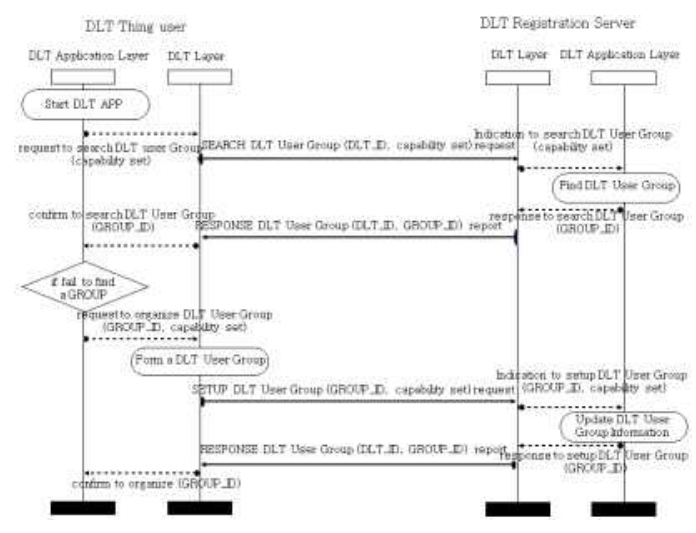

그림 7. DLT 사물유저 그룹 생성 흐름도

Fig 7. Sequence of DLT thing-user Group Creation

그림 8에서 보는 바와 같이 DLT 등록 서버가 DLT 사물유저 그룹 가입 요청을 받게 되면 DLT 사물유저 그룹에 있는 다른 사물유저에게 새로운 멤버가 가입했음을 알리고 그룹에 새로운 멤버를 추가하게 된다. DLT 등록 서버는 그룹 가입에 대한 승인 권한을 가지고 있다.

DLT 등록 서버는 새로운 사물유저가 신규 멤 버로 가입하였음을 그림 9에서처럼 그룹의 기존 멤버에게 공지하여 새로운 DLT 사물유저 그룹 의 정보를 공유하여야 한다.

\section{5. 결 론}

분산원장 기술을 기반으로 한 블록체인 기술

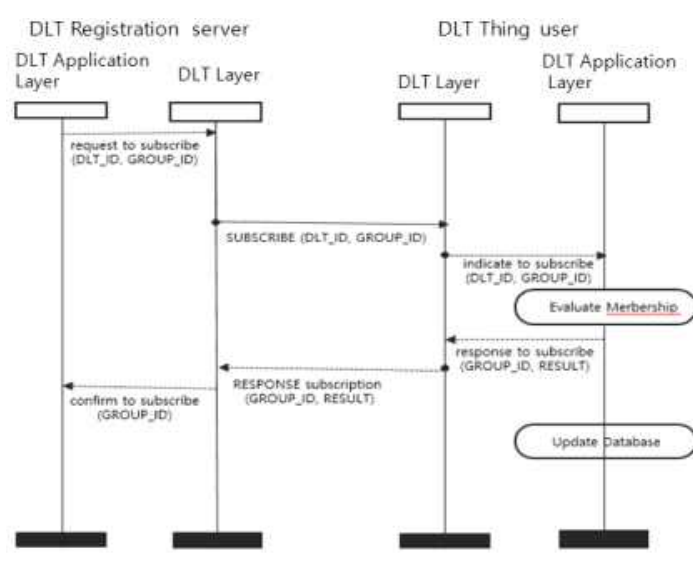

그림 8. DLT 사물유저 그룹 가입 흐름도 Fig 8. Sequence of DLT thing-user Group Subscription

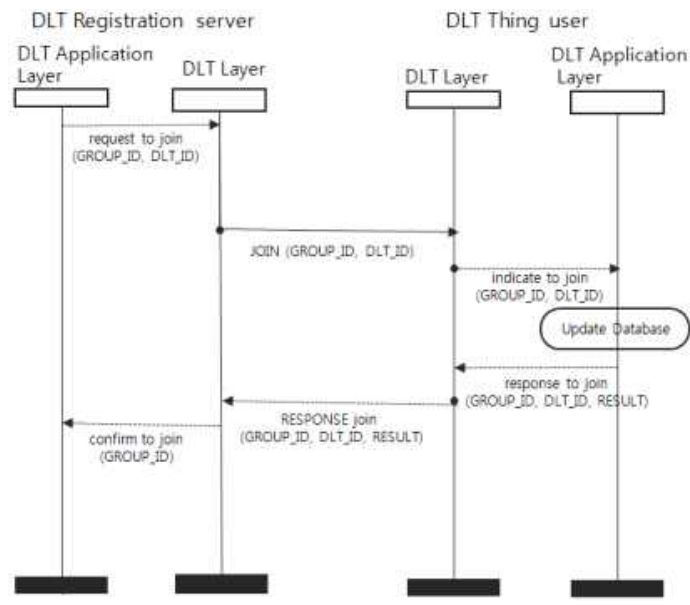

그림 9. DLT 사물유저 그룹 공유 흐름도

Fig 9. Sequence of DLT thing-user Group sharing

은 비트코인[8], 이더리움[9] 같은 전자화폐 분야 와 더불어 다양한 경제 분야(에너지, 교통, 무역, 건강관리, 전자상거래 등)의 스마트 계약 영역에 서 적용이 가능하도록 변형된 플랫폼의 형태로 만들어질 것이다. 특히 분산원장 기술은 공공기 관, 증권회사, 은행, $\mathrm{O} 2 \mathrm{O}$ 를 포함한 다양한 영역 으로 확대될 것이 분명하며 많은 개발 기관들이 함께 참여하여 국제적으로 운영되는 새로운 생태 
계를 구축할 것으로 예상한다. 이와 같이 다양한 분산원장 플랫폼이 혼재되어 운영될 것으로 예상 됨에 따라 이해 관계자의 의견을 반영한 국제표 준 제정 및 확산이 필수적임을 서로 공감하였고 이러한 추세에 맞추어 본 논문에서는 $\mathrm{ISO} / \mathrm{IEC}$ $\mathrm{JTC1} \mathrm{SC6}$ 에서 진행하고 있는 만물네트워크 표 준화와 연계하여 분산원장 기술에 대한 연구를 진행하였다. $\mathrm{ISO} / \mathrm{IEC} \mathrm{JTC1} \mathrm{SC6}$ 에서 진행하고 있는 만물네트워크 표준화 프로토콜을 기반으로 분산원장 응용 서비스 간에 호환성을 제공할 수 있고 분산원장 서비스 기능을 필요로 하는 사물 유저 그룹의 관리를 위하여 만물네트워크의 그룹 관리 기능을 제공하는 방법을 연구하였다.

그러나 본 논문에서는 분산원장 서비스를 제 공할 수 있는 사물유저 그룹을 형성하기 위한 기 본적인 구조만 제안하였고 사물유저 그룹에서 노 드 사이의 서비스 구조에 따른 실질적인 분산합 의 알고리즘의 선택방법, 트랜잭션과 블록의 데 이터 구조, 네트워크의 특성과 분산원장 서비스 의 상관관계 같은 세부적인 방안에 대하여는 해 결책을 제시하지 못하였다. 이러한 분야는 광범 히 하게 다루어 질 수 있는 분야로 추후 분산원 장 서비스 종류에 따른 분산원장 프로토콜과 망 구성에 대하여 다양한 연구가 이루어 질것으로 예상하며 이러한 연구는 ISO, ITU, IETF 같은 국제 표준화 기구와 연계하여 진행될 수 있을 것 이라 생각한다.

본 논문은 산업통상자원부의 '국가표준기술력 향상사업'의 지원에 의해 작성되었습니다. (No. 20002532)
[1] C. Decker, R. Wattenhofer, "Information propagation in the bitcoin network", 13th IEEE International Conference on Peer-to-Peer Computing, 2013, pp.1-10, doi: https://doi.org/10.1109/P2P.2013.6688704

[2] H. Cha, W. Lee, Y. Choi, J. Lee, K. Lee, "International Standardization on Blockchain”, Electronics and Telecommunications Review, Vol. 34, Issue 2, 2019. 4, pp.110-120.

[3] Burkhard Stiller, "Blockchain Fundamentals - An Assessment of Their Broad Feasibility", IFIP/IEEE IM 2019, Washington DC, U.S.A., April 8-12, 2019, https://im2019.ieee-im.org/sites/im2019.ieee -im.org/files/IM2019-Blockchain-KeynoteB-Stiller.pdf

[4] ISO/IEC TR 29181-x:2017 - Information Technology - Future Network - Problem statement and requirements, https://www. iso.org/standard/66800.html

[5] ISO/IEC 21558-3 - Information Technology - Telecommunications and information exchange between systems Future Network - Architecture, https:// www.iso.org/standard/78436.html

[6] ISO/IEC 21559-3 - Information Technology - Telecommunications and information exchange between systems Future Network - Protocols and mechanisms, https://www.iso.org/standard/ 78440.html

[7] Claudio Lime, "DLT/Blockchain Architectures and Reference Frameworks", Blockchain Engineering Council, https:// blockchain.ieee.org/images/files/pdf/2018091 7-blockchain-architecture-and-reference-fr ameworks_-_c-lima.pdf

[8] Satoshi Nakamoto, "Bitcoin: A Peer-to Peer Electric Cash System", 2008.10.31. https://www.bitcoin.org

[9] Vitalik Buterin, Ethereum Whitepaper [Internet], https://ethereum.org/en/whitepaper/

\section{참 고 문 헌}




\section{저 자 소 개}

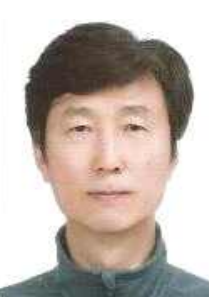

\section{김수연(Suyeon Kim)}

1988.2 경북대학교 전자공학과 졸업

1991.2 경북대학교 컴퓨터공학과 석사

2002.2 고려대학교 전자정보공학과 박사

1991.2-1997.8 한국전자통신연구원 선임연 구원

2001.2-2017.2 (주)모빌랩 대표이사

2017.3-현재 : 계명대학교 교수

<주관심분야> 통신프로토콜, 블록체인

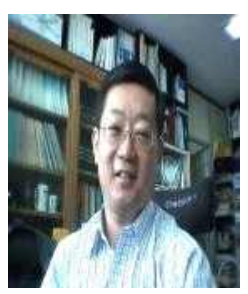

강현국(Hyun-Kook Kahng)

1982.2 고려대학교 전자공학과 졸업

1984.2 Univ. of Michigan 컴퓨터공학과 석사

1990.2 Georgia Tech. 공학박사

1991.2-1994.8 한국전자통신연구원 선임연 구원

1994.3-현재 : 고려대학교 교수

<주관심분야> 통신프로토콜, 블록체인, 웨 어러블 시스템 